\title{
A CLINICAL STUDY ON CAUSES, CHARACTERISTICS AND MANAGEMENT OF HEADACHE IN PATIENTS ATTENDING OPHTHALMOLOGY OPD AT AN APEX EYE HOSPITAL
}

\author{
K. S. Rajiv Krishna ${ }^{1}$
}

${ }^{1}$ Assistant Professor, Department of Ophthalmology, Andhra Medical College/Government Regional Eye Hospital, Visakhapatnam.

\section{ABSTRACT}

\section{BACKGROUND}

Headache is one of the common complaints in patients attending ophthalmic OPD. Stressful lifestyles with demanding studies and jobs require a lot of visual and mental focus. This aggravates eye strain in individuals resulting in various types of headache disorders. There are several other ophthalmic and non-ophthalmic causes of headache.

The objective of this study was to evaluate causes, characteristics and management of headache in ophthalmological perspective.

\section{MATERIALS AND METHODS}

500 patients with headache attending Government Regional Eye Hospital, Visakhapatnam, were clinically examined. The cause, characteristics and management of headache was analysed.

\section{RESULTS}

A majority (75\%) of the patients with headache were diagnosed to have asthenopia attributed to refractory errors. Fasih U, et al in their study obtained similar results. ${ }^{1}$ Other major causes were glaucoma and eye infections.

\section{CONCLUSION}

The most common cause of headache is refractive error, which if managed appropriately relieves patients of symptoms efficiently.

\section{KEYWORDS}

Headache, Refractive Error, Glaucoma, Squint, Migraine, Eye Disorders.

HOW TO CITE THIS ARTICLE: Krishna KSR. A clinical study on causes, characteristics and management of headache in patients attending ophthalmology OPD at an apex eye hospital. J. Evolution Med. Dent. Sci. 2017;6(79):5598-5601, DOI: $10.14260 /$ jemds/2017/1215

\section{BACKGROUND}

Ophthalmologists are often the first clinicians to evaluate patients complaining of headache associated with visual disturbances. ${ }^{2}$ Sensory innervations to the eye and periocular area arise from the ophthalmic branch of the trigeminal nerve. Thus, ocular, orbital and systemic disorders may produce head pain with ocular signs and symptoms; whereas some of these entities have characteristic diagnostic features, others mimic primary headache disorders such as migraine and cluster headache. ${ }^{3}$ In this modern era with computerisation, people are under lot of stress and eye strain resulting in various types of headaches. ${ }^{4}$ These headaches can affect the patients acutely or may lead to chronic discomfort. Consequently, apart from morbidity, academic activity disturbance in students, there is monetary loss especially in daily wage workers. Chronic headaches without proper diagnosis and management can have devastating effect on individuals, families and society. Unfortunately, sometimes patients may attempt suicide. Systematic evaluation and

'Financial or Other Competing Interest': None.

Submission 26-08-2017, Peer Review 19-09-2017,

Acceptance 25-09-2017, Published 30-09-2017.

Corresponding Author:

Dr. K. S. Rajiv Krishna,

\#2-45-14/1, GF 101,

Veitla Park View Apartment,

MVP Colony, Sector-11,

Visakhapatnam-530017, Andhra Pradesh.

E-mail: rajivkrishna9@yahoo.in

DOI: $10.14260 /$ jemds $/ 2017 / 1215$ management of headaches can be challenging at times. Optimal management will help improve quality of life and productivity.

Management ranges from refractive correction, medical treatment to surgery according to the cause.

\section{Objectives of the Study}

The objective of this study was to evaluate causes, characteristics and management of headache in our OPD patients at Government Regional Eye Hospital, Visakhapatnam.

\section{MATERIALS AND METHODS}

We performed a cross-sectional descriptive study. Patients were registered through non-probability consecutive sampling technique. A predesigned proforma was used to collect data. Data was analysed using MS Excel software.

500 patients with headache as a complaint attending the OPD at our hospital, a tertiary eye care centre were included in the study. Detailed clinical history including onset, location, duration, intensity, character, diurnal variation, aggravating and relieving factors was noted. Ocular examination included vision, slit lamp examination, cycloplegic refraction, AR, orthoptic evaluation, IOP measurement and fundoscopy. Apart from the ophthalmic evaluation thorough medical, ENT, dental and neurological evaluation was done as deemed necessary by referring the patients to those departments. Appropriate investigations like complete blood exam, x-rays, CT and MRI were done. Treatment was advised accordingly. 
Inclusion criteria in this study was patients within the age group of $15-65$. The reason for this being their ability to specifically answer the questions related to headache. Paediatric and geriatric age groups were excluded for the same reason. interval of ten years. In this study, majority were in the 36 45 age group. Compound and mixed types of astigmatism, anisometropia and miscorrection of refractive error were found more often in patients with headache. Akinci, Arsen et al in their study had correlated between headache and refractive disorders. ${ }^{5}$

\section{RESULTS}

The data was analysed by grouping the study patients into five groups. Each group was made of patients falling in the

\begin{tabular}{|c|c|c|c|c|c|c|c|c|c|c|c|c|}
\hline $\begin{array}{c}\text { Age } \\
\text { Group }\end{array}$ & No. & $\%$ & $\begin{array}{c}\text { Asthenopia/ } \\
\text { Refractive } \\
\text { Errors }\end{array}$ & Squint & Infections & Trauma & Migraine & Glaucoma & $\begin{array}{c}\text { Neuro- } \\
\text { phthalmic }\end{array}$ & \begin{tabular}{|c|} 
Intra- \\
Orbital \\
Tumours \\
\end{tabular} & Raised ICT & Idiopathic \\
\hline & & & (375) 75\% & (10) $2 \%$ & (24) $5 \%$ & (20) 4\% & (15) $3 \%$ & $(30) 6 \%$ & (2) $0.25 \%$ & (2) $0.5 \%$ & $4(0.75 \%)$ & $18(3.5 \%)$ \\
\hline $15-25$ & 72 & $14 \%$ & 54 & 1 & 4 & 3 & 2 & 4 & 0.18 & 0.36 & 0.54 & 3 \\
\hline $26-35$ & 126 & $25 \%$ & 95 & 3 & 6 & 5 & 4 & 8 & (1) 0.315 & (1) 0.63 & (1) 0.945 & 4 \\
\hline $36-45$ & 140 & $28 \%$ & 105 & 3 & 7 & 6 & 4 & 8 & (1) 0.35 & (1) 0.7 & (2) 1.05 & 5 \\
\hline $46-55$ & 110 & $22 \%$ & 82 & 2 & 6 & 4 & 3 & 7 & 0.275 & 0.55 & (1) 0.825 & 4 \\
\hline $56-65$ & 52 & $10 \%$ & 39 & 1 & 3 & 2 & 2 & 3 & 0.13 & 0.26 & 0.39 & 2 \\
\hline
\end{tabular}

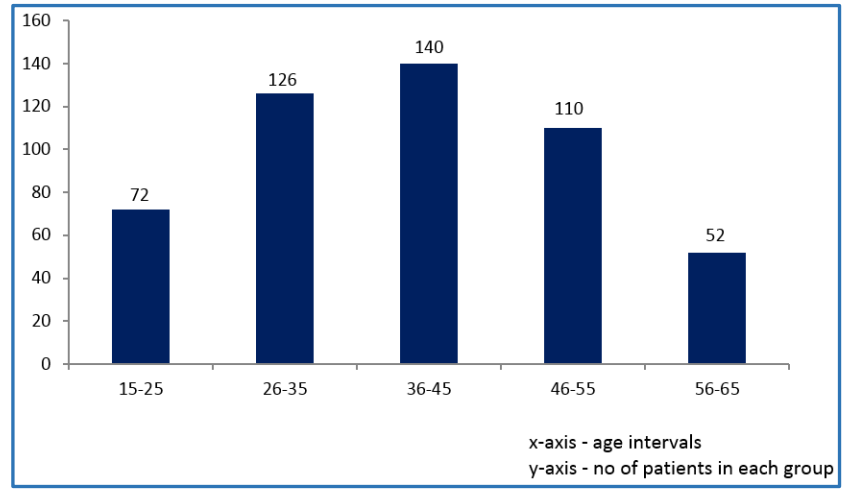

Graph 1. Age Wise Distribution

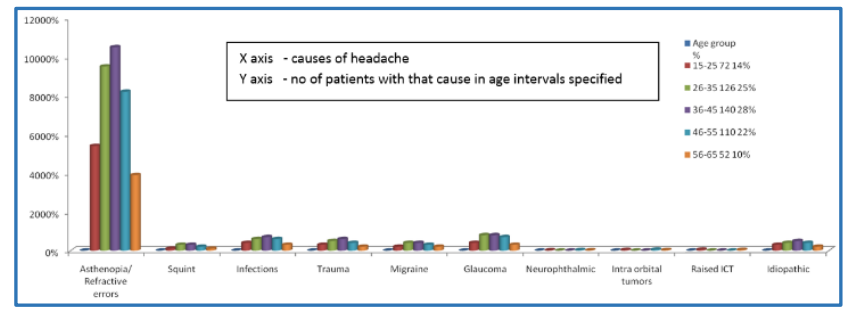

Graph 2. Showing Cause Wise Distribution

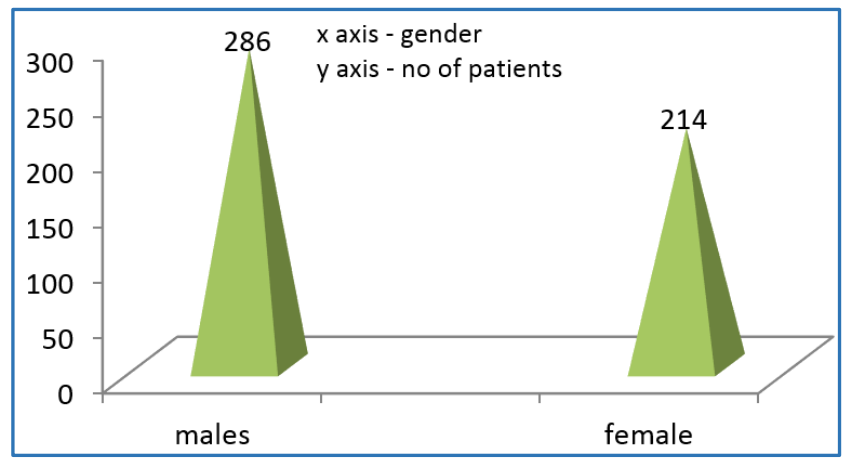

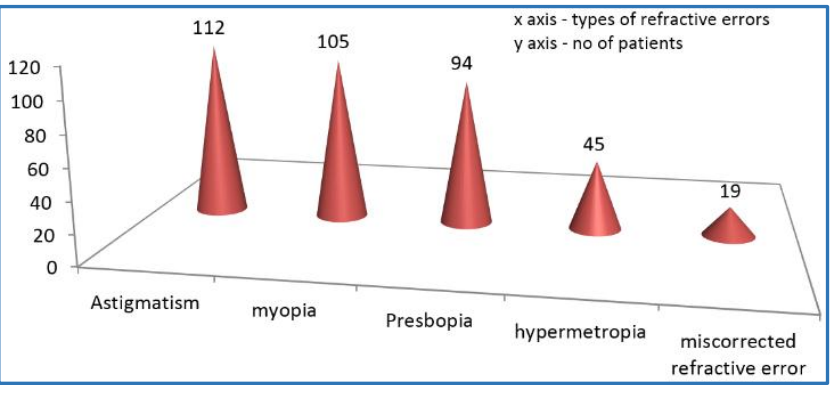

Graph 4. Various causes of Asthenopia

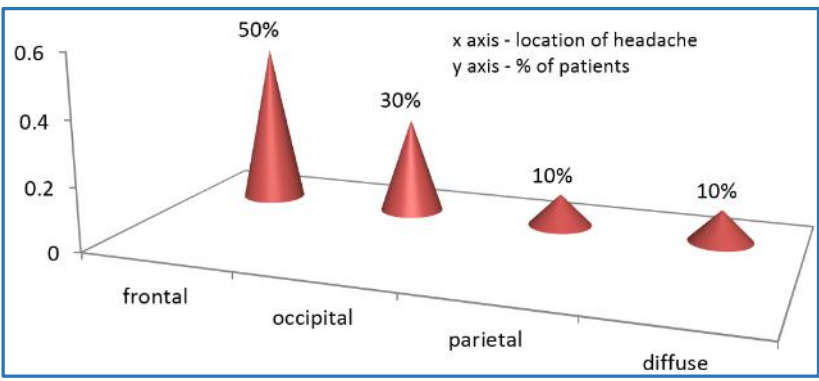

Graph 5. Showing Location of Headache

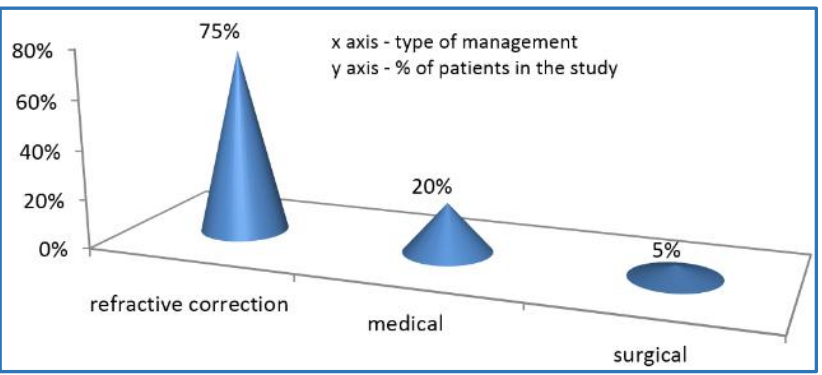

Graph 6. Methods of Management of Headache

Graph 3. Sex Wise Distribution 


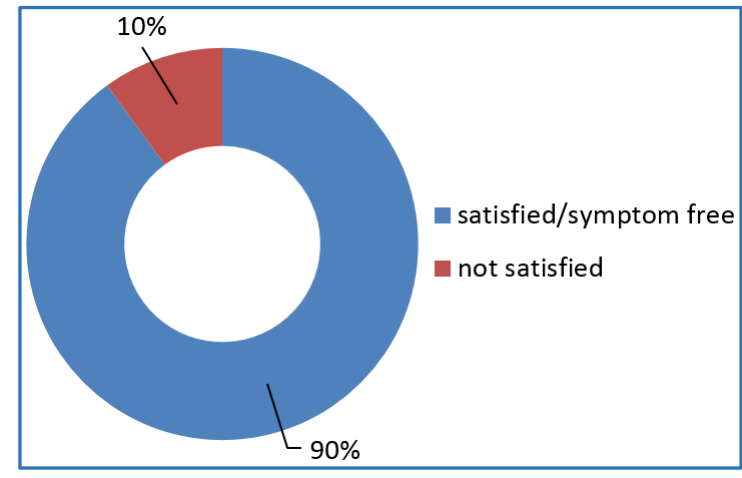

Graph 7. Outcome of Management

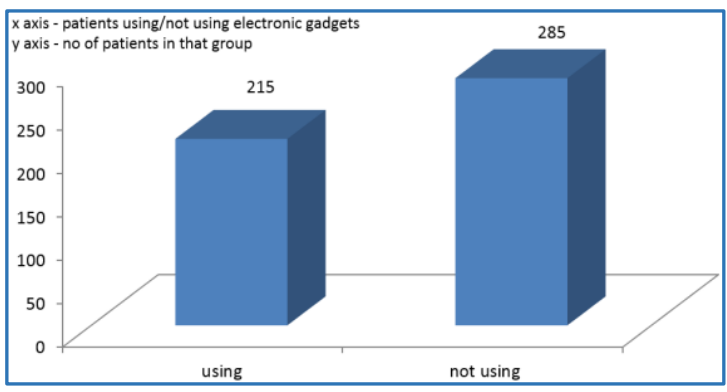

Graph 8. Showing Patients using Electronic Gadgets (215) in this Study

\section{DISCUSSION}

Headache in the Ophthalmology OPD, though very common might be challenging to assess.

It causes about $21 \%$ of people with headache having consulted an eye care practitioner for advice. These patients mostly attribute their headache to visual disorders.

There was a high prevalence of asthenopia (75\%) in our study patients. The common cause being refractive errors various studies in the literature observed the association between headache and refractive errors. $6,7,8$ Hypermetropia in $12 \%$, presbyopia in $25 \%$, myopia in $28 \%$, astigmatism in $30 \%$ and miscorrected refractory errors in 5\% were noted. Astigmatism was more prevalent in the study of Abolbashari F et al. $^{9}$ It is believed that with the rule astigmatism is less symptomatic than against the rule astigmatism.

The other causes of headache in our study were glaucoma (6\%), mainly ACG. Nesher $\mathrm{R}$ et $\mathrm{al}^{10}$ in their study took headache as presenting symptom in the cases of acute angle closure glaucomas. Infection was the cause in (5\%) of cases which included keratitis, iridocyclitis, HZO, corneal ulcer, etc. Trauma accounted for $4 \%$ and migraine for $3 \%$. The role of monocular visual symptoms and refractive errors leading to migraine were studied by Jogi $\mathrm{V}$ et al ${ }^{11}$ and Alime Gunes et $\mathrm{al}^{12}$ respectively. Idiopathic causes accounted for $3.5 \%$ and squint including both latent and manifest for $2 \%$ of the cases. Raised intracranial pressure, intraorbital tumours and neurophthalmic causes such as trigeminal neuralgias were observed in a small number of patients. B. Frishberg ${ }^{13}$ commented on headache in relation to neurophthalmology.

According to the International Headache Society, the criteria for headache related to refractive errors include. 14
1. Uncorrected refractive errors or miscorrected refractive errors.

2. Mild pain in the frontal lobe as well as in the eyes.

3. Pain that is relieved by resting and worsened by doing visual tasks at a distance or angle for a long time.

The above criteria were taken for consideration in our study.

Males (57.2\%) outnumbered females (42.8\%) and the most common site of headache in our study is frontal region $(50 \%)$ followed by occipital region $(30 \%)$, parietal $(10 \%)$ and diffuse headache $(10 \%)$ cases.

Headache due to asthenopia was managed by prescribing appropriate refractive correction. Medical management like antibiotic eye drops, anti-glaucoma drugs and NSAIDS were given depending on the clinical scenario. Some cases required surgeries like trabeculectomy in glaucomas, squint correction and exenteration in the case of intraorbital tumours.

215 patients in my study were using some form of electronic gadgets like laptops, mobile phones, etc. Though the usage may not be an attributing factor for headache directly it may aggravate the symptom, especially in the patients with asthenopia.

In this study, outcome of management is $90 \%$ of them were satisfied in the subsequent followups; $10 \%$ of them were unsatisfied, the reasons being irregular use of spectacles and non-compliance with the medication.

\section{CONCLUSION}

Ciliary muscle contraction and accommodation effort in asthenopic subject results in higher rate of headache complaints. ${ }^{15}$ Eyebrow furrowing, prolonged contraction in muscles of the brow, neck and scalp for maintenance of a clear image is another possible mechanism that leads to headache. 16

Headache is a common complaint in patients attending the eye OPD. It is very annoying to the patient. Severe headaches cause morbidity to an extent of loss of scholastics for the younger age group and loss of income in adults.

Most of these headaches can be cured well by performing accurate refraction and correct power prescription. Other headaches can be managed medically, ${ }^{17}$ especially infection and trauma related. Surgical interventions may be needed to correct squints, certain glaucomas and for tumour management.

Non-ocular causes of headache should also be kept in mind, while dealing with such patients and appropriate referrals are warranted.

Greater public awareness, regular eye check, early diagnosis and optimal treatment decrease morbidity.

\section{ACKNOWLEDGEMENTS}

I sincerely thank all the faculties of the institute, my senior residents and postgraduate students for their help. I sincerely express my gratitude to our patients for their co-operation.

\section{REFERENCES}

[1] Fasih U, Shaikh A, Shaikh N. Aetiology of headache in clinical ophthalmic practice at a tertiary care hospital of Karachi. J Pak Med Assoc 2017;67(2):166-70. 
[2] Friedman DI. Headache and the eye. Curr Pain Headache Rep 2008;12(4):296-304.

[3] Friedman DI, Gordon LK, Quiros PA. Headache attributable to disorders of the eye. Current Pain and Headache Reports 2010;14(1):62-72.

[4] Jain S, Chandravanshi SL, Dukariya L, et al. Clinical study of headache with special reference to ophthalmic cause. Int J Med Sci Public Health 2015;4(2):292-7.

[5] Akinci A, Güven A, Degerliyurt A, et al. The correlation between headache and refractive errors. J AAPOS 2008;12(3):290-3.

[6] Pan CW, Klein BE, Cotch MF, et al. Racial variations in the prevalence of refractive errors in the United States: the multi-ethnic study of atherosclerosis. Am J Ophthalmol 2013;155(6):1129-38.

[7] Kempen JH, Mitchell P, Lee KE, et al. The prevalence of refractive errors among adults in the United States, Western Europe, and Australia. Arch Ophthalmol 2004;122(4):495-505.

[8] Dandona R, Dandona L, Naduvilath TJ, et al. Refractive errors in an urban population in southern India: the Andhra Pradesh eye disease study. Invest Ophthalmol Vis Sci 1999;40(12):2810-8.

[9] Abolbashari F, Hosseini SMA, Ali Yekta A, et al. The correlation between refractive errors and headache in the young adults. Austin J Clin Ophthalmol 2014;1(3):1014.
[10] Nesher R, Epstein E, Stern Y, et al. Headaches as the main presenting symptom of subacute angle closure glaucoma. Headache 2005;45(2):172-6.

[11] Jogi V, Mehta S, Gupta A, et al. More clinical observations on migraine associated with monocular visual symptoms in an Indian population. Ann Indian Acad Neurol 2016;19(1):63-8.

[12] Gunes A, Demirci S, Tok L, et al. Refractive errors in patients with migraine headache. Semin Ophthalmol 2016;31(5):492-4.

[13] Frishberg B. Headache currents commentary. Headache 2013;53(4):717-8.

[14] Headache Classification Committee of the International Headache Society (IHS). The international classification of headache disorders, 3 rd edition (beta version). Cephalalgia 2013;33(9):629808.

[15] Eckhart B, McLean J, Goodell H. Experimental studies on headache: the genesis of pain from the eye. Proc Assoc Res Nerv Ment Dis 1943;23:209-27.

[16] Tanner JM. Growth at adolescence. with a general consideration of the effects of hereditary and environmental factors upon growth and maturation from birth to maturity. $2^{\text {nd }}$ edn. Oxford: Blackwell Scientific Publications; 1962.

[17] Jurkunas U, Gittinger JRJW. Headache and the eye. Compr Ophthalmol Update 2004;5(4). 